\section{The exercise of female sexuality between fantasy and discourse in the consumption of online pornography}

Consumption of online pornography

\author{
Mayte Cabral Mesquita and Marcelo De Rezende Pinto \\ Programa de Pós-graduação em Administração, \\ Pontificia Universidade Catolica de Minas Gerais, Belo Horizonte, Brazil
}

Received 12 February 2019

Revised 26 June 2019

13 December 2019

Accepted 21 January 2020

\begin{abstract}
Purpose - The purpose of the study is to understand how the consumption of online pornography runs through fantasy, discourse and the exercise of female sexuality.

Design/methodology/approach - First, the study analyzed a few information obtained from a secret group of the social media Facebook. Secondly, the research was developed based on the information gathered during the observation period; 11 in-depth interviews were conducted with women that participated in the aforementioned group. In order to analyze the data, the study used the French discourse analysis as methodological tool.
\end{abstract}

Findings - It was possible to realize that the consumption of pornographic content is motivated by curiosity, pursuit of variety and sexual fantasies, and it ends up strengthening stereotypes related to the concept of beauty and body standards. Also, the consumption of pornography can be seen as an important feature in the reformulation of perceptions and creation of senses related to pornography itself, pleasure, self-knowledge and in the constitution of the subjectivities of the consumers, despite the influence of the cultural context in which they are inserted into.

Research limitations/implications - The consumption of online pornography can be seen as an important "social operator"; that is, the consumption of pornography reflects and refracts what is socially established as beautiful and adequate in terms of the human figure. The outcomes of this research lead to debates that can challenge standardized world perspectives, besides expanding the discussion of such consumption made by women.

Originality/value - Taking into consideration the significant volume of pornography consumption and the high figures that this market indicates, one can notice that literature related to consumption studies has neglected this specific theme.

Keywords Consumption, Online pornography, Women, Consumption culture

Paper type Research paper

\section{Introduction}

According to the evolutionary line of consumption studies proposed by Ostergaard and Jantzen (2000), consumption currently takes on a profile that goes beyond a field related to productive forces, toward an act of maximization of utilities or an acquisition process. In a broader way, consumption became a term that seems to permeate the relationships between the society and the individual, whether in classification and social communication systems such as in processes of identity formation - in ritualistic processes or in the creation of communities (Askegaard and Linnet, 2011). In such effort, it is possible to affirm that

(C) Mayte Cabral Mesquita and Marcelo De Rezende Pinto. Published in Revista de Gestão. Published by Emerald Publishing Limited. This article is published under the Creative Commons Attribution (CC BY 4.0) license. Anyone may reproduce, distribute, translate and create derivative works of this article (for both commercial and non-commercial purposes), subject to full attribution to the original publication and authors. The full terms of this license may be seen at http://creativecommons.org/ licences/by/4.0/legalcode 
REGE 27,3 understanding the several types of consumption existing in the current social life enables the exhibition of individual and group characteristics, especially when it comes to noticing stigmas, prejudices, taboos and tensions present in social relations.

This way, the expansion of the concept of consumption ends up interweaving it with several processes and practices of the daily life, such as our relationship with objects, with food, with leisure and with entertainment moments; consumption becomes, therefore, also interwoven with the way through which we relate to our bodies and to other individuals regarding issues associated with gender, ethnics, economic classes and even with sexuality. Taking into account the latter information, there seems to be a wide spectrum of sexuality that is omnipresent in the daily life, which is strictly involved with consumption (Gould, 1991). Gould (1991) affirms that it is possible to realize a connection between sexuality and consumption in several different levels: in the sexual act per se and in the consumption of sexrelated objects, as well as in exchanges among sexual partners; in the ritualistic use of consumption objects used to attract sexual partners; and in the development of sex drive in symbolic acts or simulations of the sexual act in dances, erotic and pornographic movies.

In the context of the symbolical act of the sexual intercourse, especially in the field of eroticism and pornography, it is important to emphasize that pornography is a way used to classify cultural productions within representations of sexuality as a mediatized business considered inferior and/or vulgar. Such characteristics are different from the ones related to the concept of erotic art, which indicates more elite and culturally valued products (Leite, 2012). This way, pornography can be related to materials (images, writings, objects, among others) that - when profit-geared and market-driven - are related to something vulgar, commercialized and massified (Gregori, 2012).

The issue that seems to emerge from such discussion is related to the statement that the consumption of pornographic material exposes and registers tensions, redefinitions and fissures of the normativeness related to gender and sexuality (Gregori, 2012). When transposing the reality of pornography consumption into the virtual or online world, the discussion becomes even more complex because, due to the current phenomenon of popularization of the Internet, the pornographic content is accessible to anyone, becoming part of the daily contemporary life.

Some market data confirm such statements. According to the Associação Brasileira das Empresas do Mercado Erótico e Sensuall (ABEME, 2018), in Brazil, there are currently 11,000 points of sale that generate, directly and indirectly, more than 100,000 job positions and present revenues of more than $\mathrm{R} \$ 1$ billion annually. Regarding online pornography, Pornhub, one of the largest and most visited adult websites, developed a database dedicated to the consumption statistics of their and their partners' websites (Redtube and Youporn). According to data presented by Pornhub, the website presents an average of 92 billion video views per year, that is, around 12.5 pornographic videos watched by one person on earth. There are more than 75 million accesses to Pornhub and over 27 billion visits per year; additionally, there are 10 million users registered at Pornhub. On the other hand, the Pornhub network, which includes the websites YouPorn and Redtube, has more than 115 million daily visits. It is worth mentioning that $72 \%$ of the accesses are accomplished through smartphones and tablets (Pornhub, 2017).

Regarding the significant volume of pornography consumption, it is curious that marketing literature - and even researches related to consumptions studies - does not approach such issue, which is a wide field of discoveries to understand some phenomena of the contemporary society. In Brazil, studies that address pornography consumption are still incipient.

Another issue that deserves attention is the one mentioned by Gregori (2012), which refers to the feminization of the pornography consumption market. Such movement, which is noted both in the commercialization and consumption fields, seems to indicate, according to the author, a modification in the control of female sexuality through greater appreciation of 
sex-related products. Such notion seems to be in line with several assumptions that are related to a more free female sexuality, considering that the sexual activity for women also presents some elegant elements; while being source of physical pleasure, sex is a way to create an identity, a way for self-expression, a search for individual accomplishment (Attwood, 2006). It is specifically in the issue referring to the consumption of pornographic products in the online environment by the female audience that we identified the opportunity to conduct an empirical research in order to understand how the consumption of online pornography runs through fantasy, discourse and the exercise of female sexuality.

The choice of the subject was justified by the lack of theoretical development between the fields of sexuality and consumption; one can find a literature gap in this sense. Besides, themes related to pornography consumption by women can be still considered a taboo in the current society, despite the evident cultural progress over the past years. This study, such as other studies that deal with delicate themes, can contribute to the discussion involved in taboo subjects in order to defy narrow or conformist worldviews (Ger \& Sandikci, 2006). In the same sense and emphasizing the above-mentioned argument, sexuality - while a socially constructed category - is an essential source for the construction of subjectivities in the contemporary society (Bozon, 2004). In other words, the purpose of this paper is to fill a gap regarding the lack of research in which women that consume pornography can be heard in order to understand the way through which they realize and interpret the concept of pornography. This way, the importance of the phenomena that stem from the union between sexuality and consumption to investigate the construction of identities is evident (Walther, 2012), as well as issues related to the consumption of pornography and exercise of women's sexuality.

\section{Pornography and consumption}

The term pornography is hard to be conceptualized because there are several definitions of pornography given by several researchers, considering that the term is associated with historical and cultural beliefs permeated by moral issues, values and significances inherent to the individual.

Despite the difficulty in conceptualizing the term, Hald (2006) defined pornography as any sort of material used in order to create or increase sexual feelings or thoughts in the receptor while containing explicit exposure and/or descriptions of genital organs and clear and explicit sexual acts. In this sense, pornography refers to any sort of material related to the exposure of sexual behavior related to arousal.

From a historical perspective, the pornography known today was born during the last 30 years of the 19th century, and can be defined as the sexual representation that aims at the erotic arousal of the audience while being strictly related to the standardized production for an established market (Leite Jr, 2009).

A few decades ago, the consumption of pornography occurred in newsagent's shops, movies and video rental shops, where the privacy of the individual could not always be maintained; such places were also socially stereotyped spaces, considering that in our society, pornography is considered a morally reprehensible act (dirty and obscene) (Ribeiro Neto \& Ceccarelli, 2015). Such statement is also supported by Díaz-Benítez (2010), who affirms that pornography still remains between discourses and value judgment, between truth games and regulations, still emphasizing the tension between the named and the unnamed, being placed in unstable borders between what is considered good and bad.

In the current society, in addition to cultural changes, technology innovation has promoted the access to every and any sort of content which enabled several sorts of consumption, that is, the consumption of pornography, which became very accessible, thanks to the use of smartphones and tablets.

Consumption of online pornography 
REGE 27,3
The Internet is just another way to disseminate pornographic contents, such as photos, videos and literature (amateur and professional). However, the Internet became a privileged spot for this sort of content because it provides the consumer an ease of access, privacy protection, anonymity, ease of looking for specific genders and styles within the pornographic content and gratuity, taking into consideration that most adult websites usually do not charge any fees from users (Ribeiro Neto \& Ceccarelli, 2015).

According to Flood \& Hamilton (2003), the pornography which is popular online presents a few specific characteristics: (1) it is available through several technologies and sources, and it is presented in the form of texts and narratives, photographs, video clips available for download and web cameras with live transmissions - such features can be offered on one single website, (2) the consumption of pornography is more iterative because some websites allow real-time interaction with the individual being filmed or photographed, (3) there is a finer line between online pornography consumers and producers because there is room for the production and exchange of amateur materials in larger scales and (4) it offers a larger number of genders and highly specific categories, many times considered immoral or illegal, which are not so evident in printed productions or videos.

The individual experiences in conjunction with the cultural context, which is characterized by the system of shared beliefs, social norms, values and expectations regarding the right way to behave in certain situations, form our identities in addition to the influence on the part of parents, friends, institutions (e.g. school and church) and mass communication systems (Guerra, Andrade \& Dias, 2004). In this sense, the core issue is to question if the consumption of pornography can be seen as an influencer that enables people, based on their own experiences and interpretations of sexuality, to alter their sexual behavior progressively over time.

Regarding the specific theme of pornography consumption accomplished by women, it is possible to mention a few recent international studies: Tzankova (2015) tried to understand the consumption of pornography by women in Turkey, Chowkhani (2016) researched the risks inherent to this sort of consumption by Indian women and Hambleton (2016) investigated the increase of pornography consumption by women in contemporary Japan.

Despite the existence of a few studies, there are still little investigated issues regarding the influences of pornography consumption during the exercise of women's sexuality. Among such issues, one can find a lack of studies regarding the consumption of pornography by women in their daily lives. Another issue is related to the lack of discussions regarding reinforced stereotypes promoted by the pornography industry based on the perspective of women that consume online pornography.

\section{Methodological paths}

The empirical research conducted herein can be considered both interpretative and exploratory (Morgan, 2007; Vergara \& Caldas, 2005), in addition to a qualitative approach (Denzin \& Lincoln, 2006). It is worth mentioning the inductive characteristic of the investigation, in which we chose to give a voice to the women investigated. Our intention was not to accomplish an in-depth literature review a priori, but to investigate - after the data analysis theoretical elements that can be set against emerging categories (Charmaz, 2009).

First, we focused on the exploratory phase of the research. One of the authors of our paper participated in a secret Facebook group, called herein under the fictitious name "Talking about Sexuality," composed of women from different parts of Brazil. In November 2017, the group was composed of 12,591 members; 12 of these were group administrators responsible for the inclusion of participants, screening of posts and establishing rules for the group. This community was created in order to share experiences, photos, videos and stories whose main theme is sex, sexuality and female empowerment, in addition to bringing to discussion 
several themes involved with sexuality, pleasure, pornography consumption, among others. One of the authors of this paper was accepted in the group, and who later posted an invitation for the members to take part in the research.

Based on the material collected, which was composed of several posts, comments, tips on films and shows on pornography consumption, we elaborated an interview script that enabled the conduction of in-depth interviews with 11 women - self-declared online pornography consumers - from the abovementioned Facebook group.

The criteria used to select the interviewees were the availability and interest shown by them to take part in the research, the confirmation of the participation and the interview appointment (Bauer \& Gaskell, 2007). From the 11 interviews, 4 were conducted personally in public places previously chosen by the interviewees and 7 were conducted through video conferences using Skype. The data collection instrument was the semi-structured interview. All interviews were recorded ( $12 \mathrm{~h}$ and $59 \mathrm{~min}$ in total) and later fully transcribed.

All participants are between 20 and 38 years of age, are graduates form different areas and most of them have a university degree. Regarding their marital status, 3 are married and 8 are single (but 6 of them claim to be in a relationship). Regarding their sexual orientation, 7 of them affirmed to be heterosexual and 4 bisexual.

In the data analysis stage, we used the French discourse analysis technique as the methodological procedure. Such discourse analysis enables the analysis of interlocutions between cultural and social aspects in the construction of reality by relating theory, object and practice, allowing the researcher to understand through the discourse the history, the subject, the language and the ideology (Orlandi, 2012).

Considering that discourses present a complexity composed of several elements, the following procedures were used herein: identification and analysis of the main aspects of lexical analysis, character analysis, analysis of implicit and explicit aspects, identification and analysis of the main themes and figures (explicit or implicit) of the discourse, identification and analysis of the main interdiscursive aspects, identification and analysis of the main aspects reflected in the discourse and identification and analysis of the main aspects of the social conditions in which the discourses are produced (Saraiva, 2009).

The upcoming sessions of the paper present two emerging categories of the analysis.

\section{Consumption of online pornography and the creation of meaning in women's daily lives}

This category indicates some basic issues related to the consumption of online pornography by the women researched herein. It is possible to state that the Internet became a privileged place to spread pornographic content -, photographs, videos, literature (professional and amateur) - considering that it provides the consumer an ease of access, privacy protection, total anonymity, ease of searching for genders and specific styles within the pornographic content and gratuity, since most of the adult websites do not charge any fees from the users (Ribeiro Neto \& Ceccarelli, 2015).

The interviewees stated that they consume the pornographic content through their smartphones or laptops, and usually alone, because, according to them, it is an intimate moment for the purpose of satisfaction and self-knowledge. Even though they consume pornography online, they usually do not download any material. They prefer to consume it in their bedroom, usually at night, because such scenario makes them feel more comfortable while providing them a sense of privacy.

This way, it is important to take into consideration that the consumption of online pornographic content at night seems to be linked to the idea that such behavior indicates something forbidden, hidden and lonely. Another important issue to highlight herein is the anonymity provided by the Internet and social media (the participation of women in the secret Facebook group confirms such statement). This way, it is possible to affirm that the online
Consumption of online pornography 
REGE 27,3

version can offer a few "differentials" that are not available to other types of pornography, that is, photos, magazines, video tapes, CDs, among others.

When asked about the feature that pleases them the most in online pornography, the answers usually address factors like availability, variety, ease of access, agility and abundance of material.

(01) I like the variety. So, when I access it through Tumblr, I can find fetish-related things, different niches, and it is easy to access what I want. The niches are very diversified, one can even find some real hardcore stuff. The content is there to please anyone, regardless of people's taste. And it is easy to access no matter where you are, as long as you have access to the internet and owe a mobile phone or computer. [...] This way, every time I access there is a bunch of different things. [...] There are always more things online. They are always diversifying the content. (Interviewee 7)

In this discursive piece (01), it is clear that the variety of content and the ease of access are attractive features in this sort of consumption. There are several expressions used in this excerpt to emphasize these two characteristics of online pornography consumption presented by the interviewees: "variety," "very diversified," "to please anyone," "regardless of people's taste," "different," "bunch of different things," "diversifying." In this sense, the Internet opened a universe of possibilities for sex. From pedophilia to prostitution, anything can be found in the virtual market (Del Priore, 2011, p. 9). According to Flood \& Hamilton (2003), the pornography which is popular online presents a few particularities, for example, offering more genders and highly specific categories (sometimes considered immoral or illegal), which are not evident in printed productions or videos.

It is important to point out that, according to the discourse of the interviewees, pornography is at the service of audience entertainment and pleasure. Pornography is consumed in the pursuit of arousal and pleasure stimulation. However, curiosity, especially in the beginning, is also a motivation to consume pornography.

(02) So, wow, it was not long ago, because I think it was a sort of taboo, women were not that familiar with porno websites. [.. . .] First, it was just curiosity, and later you find out that it actually does you good. (Interviewee 1)

The curiosity refers to knowing something that is, according to her, "unknown." The curiosity is also related to seeing with her own eyes the things she already knows according to the cultural context in which she is inserted. In this sense, the expression "find out" used by the interlocutor means to discover, to learn, to expose, to disclose, to realize, to uncover, to detect. In this case, the explicit fact is to know something that "does you good"; the implicit aspect is more related to uncovering something that was previously seen as something that could only make you feel bad, something that was no good. Based on this consumption, the perception of the things that were bad was restructured and handled differently. Such restructuring is evidenced in the excerpt below.

(03) Before becoming a consumer, I felt there was this barrier. I thought it was weird, disgusting and stuff. Then, after I started to consume it, I realized it could be a tool used to stimulate myself, so it kinda ended the discrimination against the ones that actually consume it. As a consumer, every time I consume pornography I feel like I am the owner of my own pleasure because pornography was something that was not meant for women for several reasons and, suddenly, I am consuming it because I want to. So, I feel like I have total autonomy over the things that give me pleasure. (Interviewee 4).

The lexical selections "weird" and "disgusting" from the discursive piece (03) emphasize the fact that pornography consumption is seen as something bad, besides sounding like something that is not "normal" or "non-standard"; in other words, it is not in accordance with the standards established by our society, considering that pornography is usually stigmatized as something morally reprehensible (dirty and obscene), which emphasizes 
that pornography still remains between discourses and value judgment, between truth games and regulations, still emphasizing the tension between the named and the unnamed, being placed in unstable borders between what is considered good and bad (Díaz-Benítez, 2010).

In both discursive fragments (02) and (03), it is worth pointing out that the consumption of pornography was important for the interviewees to reshape their perceptions and creation of feelings regarding the pornography itself, pleasure, self-knowledge, as well as the constitution of their subjectivities by strengthening, according to Barbosa \& Campbell (2006), that the objects, goods and services count for assisting in the "discovery" or "constitution" of our own subjectivity and identity (Weinberger, 2015; Schau, 2018).

Besides, the lexical selection "because pornography was something that was not meant for women for several reasons and, suddenly, I am consuming it because I want to" demonstrates a strong discourse, an ideology that establishes the rules of the game in which women cannot consume pornography because it is not considered "women's stuff." Such discourse indicates the existence of a gender stereotype, because such behavior -consumption of pornography is understood as a purely masculine behavior. The agency power of individuals and consumers is also to be noted, considering that consumption is perceived as a social mechanism responsible for the production of senses and identity, which can also be seen as a strategy used in the everyday life of different social groups to define several situations in terms of rights, lifestyles and identities, or still as a central category in the definition of the contemporary society (Barbosa and Campbell, 2006).

However, even though some people consume pornography due to a desire to experience something new or to discover new things, individual actions of consumers are influenced above all by a wider cultural context that influences the conception of the meaning of goods and/or services consumed; in other words, consumption can also be perceived as an individual action influenced by a cultural context and by the meanings related to the society to which the individual belongs (Migueles, 2007). In this sense, the statements of Migueles (2007) can be observed in the discursive fragment (04).

(04) Consuming pornography turns me on, it brings out a curiosity in me. Right after the consumption, it used to make me feel ashamed, guilty, embarrassed. Nowadays I am much cooler with it, especially because of my religion. Today I feel more critical, so things related to guilt and embarrassment don't affect me the way they used to. These are some of the feelings that come with this consumption. (Interviewee 7)

Through the use of the expressions "ashamed," "guilt" and "embarrassment," the interlocutor highlights the influence of the cultural context in which she lives and the meanings that such consumption have in the society to which she belongs. In this cultural context, it is possible to notice a discourse (a structure) that emphasizes the consumption of online pornography as something shameful, wrong, not seen as good.

At the same time, the expression "Today I feel more critical, so things related to guilt and embarrassment don't affect me the way they used to" identified in the discursive fragment (04) indicates that the interviewee's personal choice of consuming online pornography makes her question the perspective of the cultural context in which she lives, because she no longer considers such consumption as something bad, has already redefined her perception regarding this sort of consumption and feels no longer guilty or embarrassed about it. Such perception is in accordance with Migueles (2007) when affirming that culture effectively shapes the world perspective of human beings, however, without determining them. Such excerpts indicate how consumption is shaped by social and institutional structures, such as community, gender, family and other formal groups; as consumption experience, the belief system interacts with underlying social and institutional structures (Arnould \& Thompson, 2007).

In this sense, every consumption act - including pornography - is essentially cultural and bears a symbolical exchange. The society replicates consumption according to a specific
Consumption of online pornography 
REGE 27,3 cultural logic; people do not consume generically, but based on determined choices that precede such action, to be later modified by these individuals. Therefore, culture is not a variable that overlaps and guides a universal basic consumption, but it is attached to several daily activities (Barbosa \& Campbell, 2006).

Such arguments seem to be connected to the idea that social subjects are agents of their own practice and not only reproducers of structures established by culture (Lima, 2010). In other words, on the one hand, it is possible to assume that the consumer builds "new places" and meanings for their online pornography consumption; on the other, it is impossible to neglect the social structure still present in this context, in which the role played by pornography is assumed as something negative, forbidden and therefore rejectable.

When asked about the feelings brought up by pornography, the interviewees mentioned satisfaction, pleasure, desire and curiosity. In this sense, the search for pleasure and the quest for new sensations, which are typical features of the contemporary consumer society, are also identified in the pornography consumption. Campbell (2001) emphasizes that the contemporary hedonist is an artist moved by dreams, that is, the individual that plays the role of an artist of the imagination in a process that starts with the search for images in memories or existing circumstances, and then redistributes or improves these images to turn them into something distinctly pleasant. The statements made by Campbell (2001) can be observed in the discursive fragment (05):

(05) Pleasure. Yes, it's pure desire. I like seeing pornography because it always gives me new ideas, I don't know, I wanna see different things. I imagine things. (Interviewee 3)

The feelings presented when consuming pornographic content are "pleasure" and "desire." When using the expression "I wanna see different things," the search for new pornographic content or new categories is clear, and, at the same time, the search for new sensations, which is a typical characteristic of the contemporary consumer society. Such statement also refers to Campbell (2001) when emphasizing that the capacity to fantasize is a form of hedonism. Hedonism, therefore, has as main characteristic the pleasant sensations caused by images that, despite illusory, are treated as real in order to accomplish a stimulating effect.

The perception that the consumption of pornography is related to "pleasure" and "desire" is connected to the belief that consumption provides a space for dreams, images and pleasures (Featherstone, 1995). The analysis accomplished by Featherstone (1995) indicates that, in the consumer society, most part of the production is consumption- and leisureoriented, in which it is possible to verify an expressive production of symbolical goods, images and information. It seems to be in accordance with the analysis of the discourses of the interviewees in terms of online pornography consumption. In other words, such online consumption indicates a space in which the individual has "access" to feelings and experiences, fantasies and construction of "new ideas," however, without compromising and putting their reputation at risk.

Based on the statements given by the interviewees on the consumption of online pornography, it is possible to identify a few stereotypes present in the pornographic content. Such theme will be discussed in the following section.

\section{Stereotypes reinforced by the pornographic industry}

Two issues emerged in a very evident way when analyzing the discourses. One of these issues is related to beauty and the complexity brought up by such concept. The other issue is related to the body as a translation of the symbolic system shared among members of the community (Le Breton, 2007).

Regarding beauty, it is adequate to emphasize that this has become an important theme in several knowledge areas, including marketing and consumption studies. The representations 
of beauty are strongly related to cultural issues, considering that beauty is universal only as a concept; however, in its manifestation, it becomes singular as it is influenced by the cultural context in which it is inserted (Vacker \& Key, 1993).

By analyzing the interview discourses, it became clear that, regarding the actresses of pornographic movies, most of them own the body figure considered as the beauty standard of the Western society: white skin, long and blonde hair, large breasts, voluptuous buttocks and slim waist. This standard can be observed in the following excerpt, which refers to the sort of women that are mostly shown on pornographic films and videos:

(06) I think that women with breast implants are the ones that fit the most, the ones with that perfect belly, straight blonde hair, and giant fingernails. (Interviewee 5)

(07) The women that fit the beauty standards that we have nowadays are for sure the ones with thin figure, silicone implants, huge breasts, perfect butt, long hair. (Interviewee 10)

These two discursive fragments indicate through the terms "breast implants," "perfect belly," "straight blonde hair," "thin," "silicone," "huge breasts" and "long hair" that the characteristics perceived and mentioned by these two interlocutors are attributes related to hegemonic standards of beauty, which emphasize the blonde, straight haired, thin and big breasted woman, regardless of the use of silicone prosthesis.

In the discursive fragment (07), the lexical expression "The women that fit the beauty standards that we have nowadays" indicates the existence of a stereotype of female beauty in society, which can also be noted in the pornographic content mentioned by the interviewees. Such perception is ratified by Díaz-Benitez (2010) when affirming that pornographic movies maintain and affirm the prevalence of figures that correspond to hegemonic beauty standards. The interlocutors realized such fact, which is emphasized in the following discursive fragment.

(08) [ . . . That regular standard, white, blonde or very beautiful brunettes, always this standard [ . . ]

Always very hot or very skinny women. Always this kind of woman. (Interviewee 7)

The lexical selection "That regular standard" in the discursive fragment (08) reveals explicitly that in pornographic contents, there is a hegemonic standard imposed by society, that is, a rule that is accepted by society. The implicit fact is that women that do not meet such standards, that is, women that do not have the characteristics determined as the ideal of beauty or women that do not meet such standards are not those present in pornographic contents; they are excluded and marginalized, which corroborates with other spheres of society, such as in work relations and school. In other words, it becomes evident that this interviewee criticizes this hegemonic beauty standard.

According to the previous excerpts, such standard is strengthened though the discursive fragment (09) provided by interviewee (4), who states her opinion regarding the type of woman emphasized by the pornographic industry.

(09) The standard woman. It's obvious. Most of the times it's a woman with a predetermined body shape, a predetermined breast size, a predetermined butt size, a predetermined hair type. Regarding women, it is quite clear that there is a standard required in terms of body shape in order to play a part on a pornographic movie. (Interviewee 4)

When affirming "It's obvious" and "it is quite clear that there is a standard required in terms of body shape in order to play a part on a pornographic movie," the interviewee treats the theme as if this beauty standard were an "absolute truth" and makes clear that the pornographic industry imposes a beauty standard to actresses. It is worth mentioning that, instead of being an imposition made by the pornographic industry, it may actually be a reproduction of standards imposed by the society itself. At the same time, it is explicit that the
Consumption of online pornography 
REGE 27,3 imposition of a beauty standard is more required from women than from men; such a statement is supported by the lexical selection "Regarding women."

Another stereotype strengthened by the pornographic industry and mentioned by the interviewees is the perception that black women are often seen as reproducers and as people that can take "everything." Such vision refers to the historical sexualization of black people, which started to occur during the slavery period in Brazil, in which the black community especially women - was diminished and objectified by the society (Siqueira, 2008; Ribeiro, 2006). The following discursive excerpts presented below exemplify such perception.

(10) [. . . Always in regular porno movies the black woman is very, very, very sexualized. It's that thing... I don't know. They all are. (Interviewee 6)

(11) [...] For example, I think that porn usually strengths the perception that black women are reproducers, they can always bear some more. (Interviewee 11)

These discursive fragments work as aspects reflected on the socially established discourse regarding the racial sexualization of the black woman; in other words, the sexualization of the black woman is strengthened in pornographic contents, which is an aspect present in other spheres of the society, in addition to being an historical issue.

Another issue that must be mentioned herein is that the female standard disseminated by the pornographic industry seems to bother the women interviewed, once it is perceived as something unreal and unreachable according to the statements below.

(12) [... ] I don't know, body figures that are not very real. (Interviewee 5)

(13) $[\ldots]$ in the pornographic material I have access to I always see thin women, known as "potrancas2", huge butt, huge breast, very skinny, but a little unreal. You can't see women like that easily on the street. (Interviewee 7)

(14) In the classic porno, it is the paniquete3. She is hot, [. . . ] has a very tight butt, a very defined butt, very defined legs. It is a silicone industry. That thing that just doesn't exist. (Interviewee 11)

When using the expressions "not very real" (Interviewee 5), "but a little unreal" (Interviewee 7) and "That thing just doesn't exist" (Interviewee 11), the interlocutors seem to believe that this standard, which is spread and worshiped, is not met by people because it is unreal; it is an ideal and unreachable standard due to several factors, with racial, economic, psychological implications, which supports the idea of Vacker \& Key (1993) when referring to the impossible beauty.

In the expression "thin women, known as 'potrancas', huge butt, huge breast, very skinny," there is an implicit reference to beauty as appearance (in addition to the abovementioned discursive fragments (06), (07) and (08)), which is related to the shallowness of beauty, that is, a person can become attractive if he/she has this type of beauty (Vacker \& Key, 1993). In order to reach such beauty standard, some people live out their lives according to their body shape, dedicate several hours of their lives to the gym, are always on some miraculous diet, undergo esthetic procedures and surgical interventions, besides spending a significant amount of money in search of the ideal beauty. Many times, these individuals become so obsessed that they start having health problems, such as anorexia and bulimia, and even commit suicide due to the everlasting unsatisfaction with their own bodies or for not reaching the ideal beauty standards.

Regarding the actors, there is a wider variety in terms of physical characteristics; there is the white man, the hot one, the chubby one and the black man. However, they all have in common one characteristic: their penises must be thick and large. This standard can be observed in the following excerpts, which refer to the most common male stereotype observed in pornographic movies and videos. 
(15) Hot men and huge cock. The cock must be thicker than larger. (Interviewee 3)

(16) I think men are more diverse, but their dicks are always thick and large. There is the white standard guy, the muscular one, and the black guy, who is always the fetish stereotyped kind: with a large dick, with a very huge cock. But I see more diversity in men. (Interviewee 7)

(17) Man. . . I see no physical standards. Because I've already seen movies with bellied guys, with hot ones, but the dick must be large and thick. I've never seen a porno movie without a guy with a super dick. (Interviewee 10)

The physical characteristics of actors are rarely mentioned; this way, the male beauty standard accepted by the society to which the interlocutors belong is not strengthened by the pornographic industry. However, the attribute "thick and large penis" was mentioned by the interviewees as an important feature in the porno world, since it is a common characteristic of male actors and refers to masculinity, symbolizing virility and sexual potency. Such characteristic can be seen in the following excerpts.

(18) Every time I see the guy he is ... Well, he is not handsome, but his cock is always huge, always very huge. It is always this kind of guy; this is the standard. (Interviewee 6)

(19) [...] It's the strong guy, the alpha male, with the hugest cock they can find to put there. The largest cock they can get and to film it from the most incredible angles to give the viewer the sensation that the guy's cock is 30 centimeters long. (Interviewee 8)

The female and male patterns disseminated by the pornographic industry raise expectations, create complexes and intensify the low self-esteem not only of women but also of men. Some women understand that in order to please their partners, they must look exactly like porno actresses. And men believe that, in order to demonstrate their masculinity and please their partners, they must have the same genital size as the ones portrayed in videos and movies. Supporting the affirmations given by the interviewees, Cabral \& Romeiro (2011) indicate that the human sexuality sadly can be summed up in the imperative of the perfect sex and the fabulous orgasm, neglecting all esthetic, ethical and loving possibilities of sexuality. According to the authors, there is an implicit submission in the excessive appreciation of body shapes, one that in the perfect figure the individual becomes a mere object of consumption.

In this point, it is worth bringing out some brief discussions on the issue of the body and its relation to the consumption of online pornography. According to Le Breton (2007), the body is the axis of the relationship with the world, the place and time in which the existence takes shape through the singular physiognomy of an actor. Through the body, humans appropriate the substance of life using symbolic systems that are shared with members of the community. According to Shilling (2012), the body seems to be a central piece for our capacity to intervene or to exert agency in the world, as well as expressing emotions, preferences, capacities and sensorial actions that end up being a fundamental source of "social forms."

Based on the discussion provided by these authors, it is worth mentioning that the body is shaped by several instances of society that attribute esthetic and physical characteristics that start constituting a model of beauty. Such consideration is aligned with the discourses made by the women interviewed herein in terms of what they consider as a sexually attractive or physically beautiful body shape.

Bringing such concept to the consumption field, it is possible to affirm that the body is in the center of important markets and consumption practices (Valentim, Falcão, \& Campos, 2017), which seems to bring to the statement that the consumption of online pornography is an important social "operator"; in other words, the consumption of pornography ends up reflecting and refracting what is socially established as beautiful and appropriate in terms of body shape.

Consumption of online pornography 
REGE 27,3

\section{8}

The body, however, as an object of consumption, can be evidenced in the discursive fragment below.

(20) I think that porn, for example, it encourages such bad thing, because you end up creating a standard. We, women, have to be paniquetes; men, even being white, have to be Kid Bengala4. (Interviewee 11)

(21) There is a standard of what men have to be. Like, the guy must have a big cock, the guy has to hold on for I don't know how many hours, the guy has to ... I think this is why the masculinity of men are susceptible to anything. (Interviewee 11)

The term "we" indicates a placement as the subject of the discourse, both as women and as community. Besides, the expressions "have to be" and "must" refer to obligations, an imposition of the standard, which is certainly related to frustration in people and the possible reason for the emergence of insecurity in the sexual intercourse, which might lead to the conclusion that sex is not pleasant. It all affects love, family and social relations in a bad way, which emphasizes the idea of Cabral \& Romeiro (2011) when affirming that the excessive appreciation of the human figure hides a disguised submission, which limits human sexuality and neglects all esthetic, ethical and loving possibilities of sexuality.

In the discursive fragment (20), the name of the porno actor is used as a label, a symbol of sexual potency. The actor mentioned (Kid Bengala) is a Brazilian pornographic actor known for the size of his sexual organ. When claiming "even being white," it is possible to notice an explicit aspect, which represents an assumption of the common sense that white men do not usually have large penises and, at the same time, indicates an implicit aspect in which the black man is the one that owes such feature.

It was possible to realize in this session, as well as through the analysis of the interviews, that pornography strengthens the stereotypes adopted by society in terms of ideal standards, which can cause anxiety and frustration in consumers.

\section{Final considerations}

Now that we have reached the final considerations, the first point we want to emphasize is that this research should not be seen as a finishing line with several conclusions and findings regarding the theme researched herein. Au contraire, considering that the purpose of this study was to understand how the consumption of online pornography runs through fantasy, discourse and the exercise of female sexuality, it is worth emphasizing that the research should be understood as a starting point to uncover several issues still pertinent in the consumption of pornography by this group of individuals.

This way, some issues can be considered. The consumption of online pornography according to the interviewees occurs mainly through smartphones and laptops without the presence of their partners, because they consider this moment as something intimate used to pursue satisfaction and self-knowledge, which indicates that the idea of such consumption might be related to something prohibited, hidden and lonely. The Internet enabled several changes regarding the consumption of pornography - once the web provides anonymity, there is no need to identify the user when accessing pornographic material; also, there is ease of access, because the content can be accessed from anywhere. There is a large availability, variety and abundance of pornographic material online, in addition to the ease and agility of access as well as gratuity.

Curiosity is one of the main motivations of this consumption, considering that the purpose is to know things that are considered unknown, denied and bad. Through this consumption, it is possible to give new meaning to pornography, which starts being faced as a choice that is allowed and that can do some good. This way, the consumption of pornography is an important issue in the reformulation of perceptions and creation of 
senses regarding pornography itself, pleasure, self-knowledge, as well as the constitution of the subjectivity of the consumers, despite the influence of the cultural context to which consumers belong. It is possible to state that the individual choice of consuming online pornography leads to questionings regarding the perspective of the cultural context to which people belong.

In a certain way, the consumption of online pornography can be understood as a space in which the individual has "access" to sensations and experiences, liberation of phantasies, construction of "new ideas," however, without compromising and without putting their reputation and image at risk, which is enabled thanks to the ease of access, content diversity and anonymity.

It is possible to state that the pornographic industry strengthens stereotypes, once the actresses and actors that play parts in movies have several common physical characteristics, considering the existence of a hegemonic beauty standard imposed by the society. Regarding the actresses, most of them have the body figure considered as the beauty standard of our Western society: white skin, long blonde hair, large breasts, defined buttocks and thin waist; additionally, it is evident that such standard is required more from women. In this sense, the cultural beauty standards are an imperative for people, especially women. If they do not "fit in," these standards cause discomfort to the women interviewed herein, once they consider such ideal beauty as unreal.

Complementarily, it is possible to affirm that the consumption of online pornography is seen as an important social "operator," that is, the consumption of pornography ends up reflecting and refracting features that are socially established as beautiful and adequate in terms of body shape. It is also possible to state that the female and male "standards" disseminated by the pornographic industry cause a few expectations, create complexes and intensify the low self-esteem of both women and men, because some women understand that in order to please their partners, they have to look exactly like the porno actresses; and men believe that in order to prove their masculinity and please their partners, they have to have the same sexual organ as the ones presented in porno videos and movies.

This way, the results of the research seem to bring out reflection forms that can contribute to the discussion of the taboo regarding the consumption of pornography by women and challenge standardized world perspectives, in addition to expanding the discussion regarding the theme and bringing a new perspective on this field of research, clarifying social and cultural issues that permeate the symbolic university of the consumption culture in which the woman that consumes pornography is still judged and susceptible to prejudice.

It is important to mention herein that the findings of the research also point out issues that go beyond the consumption of pornography; such matters can contribute to the demystification of issues related to the female experiences regarding the offering of several products, such as underwear, perfumes, cosmetics, erotic items, as well as services related to tourism, entertainment and erotism.

Retrieving the statements made in the beginning of this section, this study seems to bring to the researchers of this field several new study possibilities that can encompass conducting of researches with other groups, such as teenagers, elderly people and consumers with distinct sexual orientation. Additionally, emerging issues found in the analysis, such as the dichotomy agency (individual curiosity that leads to consumption) versus structure (represented by taboos that lead to guilt and embarrassment), could promote fruitful discussions for public policies that support female sexuality, such as policies for combating violence and sexual exploitation of women. In the same sense, the study clarifies the sexual habits of women, which can contribute to public policy campaigns that focus on the prevention of sexually transmitted diseases.

It would be interesting to investigate the development of investigations that tried to relate forms of socialization of sexual practices through pornography with the support of

Consumption of online pornography 
REGE 27,3

\section{0}

Transformative Consumer Research (TCR). It is important to point out that the theme is relevant to transformative consumer research, considering it can proceed with the discussion on the articulation between pornography, sexuality and women's empowerment. Another suggestion would be to understand the pornography market under the perspective of market dynamics. Other data collection techniques and data analysis, in addition to the ones presented herein, could be useful for the consolidation of this fruitful research field.

\section{Notes}

1. In English, Brazilian Association of Erotic Markets.

2. Brazilian slang used to describe sexy young women.

3. Brazilian word that refers to some sexy TV hostesses of an already canceled TV show.

4. Reference to a Brazilian porno actor known for the large size of his penis.

\section{References}

ABEME. Associação Brasileira das Empresas do Mercado Erótico e Sensual. Disponível em. Available at: https://www.abeme.com.br/. Acesso em 22 de abril de 2018.

Arnould, E.J., \& Thompson, C. (2007). Consumer culture theory (and we really mean theoretics): Dilemmas and opportunities posed by an academic branding strategy. In Belk, R.W., \& Sherry, J.F. Jr (org.). Consumer Culture Theory, Oxford: Elsevier, 3-22.

Askegaard, S., \& Linnet, J.T. (2011). Towards an epistemology of consumer culture theory Phenomenology and the context of context. Marketing Theory, 11(4), 381-404.

Attwood, F. (2006). Sexed up: Theorizing the sexualization of culture. Sexualities, 9(1), 77-94.

Barbosa, L., \& Campbell, C. (2006). O estudo do consumo nas ciências sociais contemporâneas. In Barbosa, L., \& Campbell, C. (Orgs.). Cultura, Consumo e Identidade. Rio de Janeiro: Editora FGV.

Bauer, M.W., \& Gaskell, G. (2007). Pesquisa qualitativa em texto, imagem e som. Petrópolis: Vozes.

Bozon, M. (2004). Sociologia da sexualidade. São Paulo: FGV Editora.

Cabral, R.V., \& Romeiro, A.E. (2011). Sobre a sexualidade controlada: Poder e repressão sexual em Michel foucault. EDUCAÇÃO, 1(1), 87-106.

Campbell, C. (2001). A Ética Romântica e o Espirito do Consumismo Moderno. Rio de Janeiro: Rocco.

Charmaz, K. (2009). A construção da teoria fundamentada: Guia prático para análise qualitativa. Porto Alegre: Artmed.

Chowkhani, K. (2016). Pleasure, bodies and risk: women's viewership of pornography in urban India. Porn Studies, 3(4), 443-452.

Denzin, N.K., \& Lincoln, Y.S. (2006). O planejamento da pesquisa qualitativa: Teorias e abordagens. 2nd ed. Porto Alegre: Artmed.

Díaz-Benítez, M.E. (2010). Nas redes do sexo: Os bastidores do pornô brasileiro. Rio de Janeiro: Zahar.

Del Priore, M. (2011). Histórias intimas: Sexualidade e erotismo na história do Brasil. São Paulo: Editora Planeta do Brasil.

Featherstone, M. (1995). Cultura de Consumo e Pós-modernidade. São Paulo: Nobel.

Flood, M., \& Hamilton, C. (2003). Youth and Pornography in Australia: Evidence on the extent of exposure and likely effects. Discussion Paper No. 52. The Australia Institute, Camberra.

Ger, G. \& Sandikci, O. (2006). Doing researsh on sensitive topics: Studying covered Turkish woman. In Belk, R.W. (Ed.). Handbook of Qualitatuve Researsh Methods in Mareketing, Glos: Edward Elgar Publishing. 
Gould, S.J. (1991). Toward a theory of sexuality and consumption: Consumer lovemaps. Advances in Consumer Research, 18, 381-383.

Gregori, M.F. (2012). Erotismo, Mercado e gênero: uma etnografia dos sex shops de São Paulo. Cadernos Pagu, (38), 53-97.

Guerra, V.M., Andrade, F.C.B.de, \& Dias, M.R. (2004). Atitudes de estudantes universitários frente ao consumo de materiais pornográficos. Estudos de Psicologia, 9(2), 269-277.

Hald, G.M. (2006). Gender differences in pornography consumption among young heterosexual Danish adults. Archives of Sexual Behavior, 35(5), 577-585.

Hambleton, A. (2016). When women watch: The subversive potential of female-friendly pornography in Japan. Porn Studies, 3(4), 427-442.

Le Breton, D. (2007). A sociologia do corpo. 2a. Tradução de Sônia M. S. Fuhrmann. Petrópolis, RJ: Vozes.

Leite, J. Jr (2009). A pornografia "bizarra" em três variações: a escatologia, o sexo com cigarros e o "abuso facial". In. Díaz-Benitez, Maria Elvira e Fígari, Carlos Eduardo. (orgs.) Prazeres Dissidentes. Rio de Janeiro: Garamond.

Leite, J. Jr (2012). Labirintos conceituais científicos nativos e mercadológicos: Pornografia com pessoas que transitam entre os gêneros. Cadernos Pagu (38), 99-128.

Lima, D.N.O. (2010). Consumo: uma perspectiva antropológica. Petrópolis-RJ: Editora Vozes.

Migueles, C. (2007). Antropologia do consumo: Casos brasileiros. São Paulo: FGV Editora.

Morgan, D.L. (2007). Paradigms lost and Pragmatism regained: Methodological implications of combining qualitative and quantitative methods. Journal of Mixed Methods Research, $1(1), 48-76$.

Orlandi, E.P. (2012). Análise de discurso: Princípios e procedimentos. 10. Campinas: Pontes Editores.

Ostergaard, P., \& Jantzen, C. (2000). Shifting perspectives in consumer research: From buyer behavior to consumption studies. In: Beckmann, S., \& Elliott, R.H. Interpretive Consumer Research: Paradigms, Methodologies and Applications. Copenhagem Business School Press.

Pornhub, (2017). Pornhub Statistics. Recuperado a partir de Available at: https://www.pornhub. $\mathrm{com} /$ press.

Ribeiro, D. (2006). O Povo Brasileiro: A formação e o sentido do Brasil. São Paulo: Companhia das Letras.

Ribeiro Neto, A., \& Ceccarelli, P.R. (2015). Internet e pornografia: notas psicanalíticas sobre os devaneios eróticos na rede mundial de dados digitais. Reverso, 37(70), 15-22.

Saraiva, L.A.S. (2009). Mercantilização da cultura e dinâmica simbólica local: a indústria cultural em itabira, Minas gerais (tese de doutorado). Centro de Pesquisas e Pós-graduação em Administração, Universidade federal de Minas gerais, Belo Horizonte, MG, Brasil.

Schau, H.J. (2018). Identity Projects and the Marketplace. In Arnould, E.J., \& Thompson, C.J., Consumer Culture Theory. London: Sage Publication.

Shilling, C. (2012). The Body and Social Theory. 2nd. edition. London: Sage Publications.

Siqueira, F.R.M. (2008). História da Sexualidade Brasileira. São Paulo: Leitura Médica.

Tzankova, V. (2015). Watching porn in Turkey: women, sex, and paradigm shifts. Porn Studies, 2(2-3), 208-221.

Vacker, B., \& Key, W.R. (1993). Beauty and the beholder: The pursuit of beauty through commodities. Psychology \& Marketing, 10(6), 471-494.

Valentim, P.P., Falcão, R.P.Q. \& Campos, R.D. (2017). O corpo nos estudos de consumo: Uma revisão bibliográfica sobre o tema. Consumer Behavior Review, 1, 32-48.

Vergara, S.C., \& Caldas, M.P. (2005). Paradigma interpretacionista: a busca da superação do objetivismo funcionalista nos anos 1980 e 1990. Revista de Administração de Empresas, 45(4), 66-72.

Consumption of online pornography 
REGE

27,3
Walther, L.C.C.L. (2012). Consumo erótico feminino e Cultura Material (Tese de Doutorado). Universidade Federal do Rio de Janeiro, Programa de Pós-graduação em Administração, Rio de Janeiro.

Weinberger, M.F. (2015). Dominant consumption rituals and intragroup boundary work: How noncelebrants manage conflicting relational and identity goals. Journal of Consumer Research, 42(3), 378-400.

\section{Corresponding author}

Marcelo De Rezende Pinto can be contacted at: marcrez@hotmail.com

Associate Editor: Sofia Ferraz

For instructions on how to order reprints of this article, please visit our website: www.emeraldgrouppublishing.com/licensing/reprints.htm Or contact us for further details: permissions@emeraldinsight.com 